\title{
Design and Analysis of a Fault Tolerant Permanent Magnet Alternator for Aerospace
}

\author{
M. C. Kulan, N. J. Baker, S. Turvey
}

\section{Presented at XXIIIrd International Conference on Electrical Machines \\ (ICEM'2018). 2018, Alexandroupoli, Greece: IEEE. Newcastle university E print version}

\begin{abstract}
In this paper, 28 slot-18 pole and 24 slot-20 pole permanent magnet alternators (PMA) with soft magnetic composite slot wedges are designed and compared. Power lane separation required due to fault tolerance requirements, means the proposed machines initially do not produce balanced phase voltage and currents, resulting in high ripple on the rectified power output. The alternators are optimised using 2-D finite element analysis (FEA) to get smoother DC power waveform. It is shown that the power ripple might be reduced by about $12 \%$ and un-balanced windings can be significantly balanced by thickening up the SMC slot wedges between the sub-machines. Furthermore, no load loss analysis has been conducted at rated speed and it is shown that 28s18p machine generates lower loss on no load condition compared to 24s20p single layer PMA.
\end{abstract}

Index Terms-- Alternator, aerospace, fault tolerance, finite element analysis, magnetic wedge, permanent magnet machine

\section{INTRODUCTION}

A dedicated fault tolerant power generation system is crucial for the engine control unit in aerospace applications, which is usually based on permanent magnet (PM) machines due to high power density, low volume and weight for a given torque rating compared to wound rotor designs [1]. The permanent magnet alternator (PMA) in an aerospace engine is directly driven from the engine gearbox via a dedicated low speed output to provide constant power across a wide engine speed range [2-3]. The low speed power requirement drives the magnetic design and slot wedges are used to increase the inductance and limit current and power output at high speeds.

The principal reason for a dedicated generator as part of the engine control electronics suite is due to the prevent loss of aircraft power causing a thrust control failure on a large civil aircraft. The engine control suite, however needs to be powered from an uninterruptable source. For this reason, fault tolerant permanent magnet alternators are an important part of aero-engine control units.

The adoption of fractional slot concentrated windings in PM machines enables electric, magnetic and thermal separation so that distributed windings can be avoided in such fault tolerant designs. Recently, non-overlapping single tooth windings are considered as high reliability solution for aerospace as they can inhibit short circuit current [4] yet high

This work is fully funded by Rolls Royce and Innovate UK.

M. C. Kulan and N. J. Baker are with the School of Engineering, Newcastle University, Newcastle Upon Tyne, NE1 7RU, UK (mehmet.kulan@newcastle.ac.uk ; nick.baker@newcastle.ac.uk) magneto motive force (MMF) and large slot openings are disadvantageous due to high induced eddy-current losses in rotating parts of the machine [5-6].

In this paper, two fault tolerant PM alternators having the same volume envelope have been designed using FEA. A detailed comparison of the characteristics of the surface PM machines with soft magnetic composite (SMC) magnetic slot wedges is presented. Soft magnetic composites, which consist of iron powder particles coated with insulation can provide 3dimensional magnetic flux paths [7]. Although SMC usually has a lower relative magnetic permeability in comparison to conventional electric steels, they are well suited to couple machine parts magnetically, provide relatively easy manufacturing [8] and provide a great freedom in terms of geometric shape. High permeability SMC magnetic wedges hence might be useful in the design of fault tolerant PMAs in order to limit short circuit currents.

The proposed machines will have four star connected, 3phase independent outputs implying that the complete machine must allow galvanically isolated sub-machines within the given volume. Since aero-engine systems usually impose well defined dimensional constraints for the machine integration, Table I shows the maximum available length and diameter for the PMA design along with the other design constraints.

TABLE I. KEY SPECIFICATIONS OF THE PMA

\begin{tabular}{|c|c|}
\hline Stator outer diameter & $190 \mathrm{~mm}$ \\
\hline Stack length & $30 \mathrm{~mm}$ \\
\hline Line to line RMS back EMF at $15000 \mathrm{rpm}$ & $230 \mathrm{~V}$ \\
\hline Power delivered from each sub-machine at $400 \mathrm{rpm}$ & $40 \mathrm{Watts}$ \\
\hline $\begin{array}{c}\text { The maximum short circuit current at } 15000 \mathrm{rpm}- \\
\text { per phase }\end{array}$ & $20 \mathrm{~A}_{\mathrm{rms}}$ \\
\hline $\begin{array}{c}\text { Speed range } \\
\text { Insulation system life expectancy }\end{array}$ & $0-15000 \mathrm{rpm}$ \\
\hline
\end{tabular}

As tabulated in Table I, there are two design points. Firstly, the output power of the each sub-machines must be at least 40 Watts at low speed: $400 \mathrm{rpm}$. Secondly, the PMA must be fault tolerant and the maximum short circuit current flowing from

S. Turvey is with Rolls-Royce Controls and Data Services, York Road, Hall Green, Birmingham, B28 8LN, UK 
any pin on the machine shall not exceed $20 A_{r m s}$ at $15000 \mathrm{rpm}$, rated speed. The peak phase back EMFs are also limited and they shall not exceed 187.8 Volts at rated speed. The PMA spends much of the time at short circuit to limit the output power [3]. Therefore, high speed losses might be of importance in the machine.

The requirement for high inductance necessitates small slot openings or the use of magnetic wedges [9]. This complicates the fabrication process yet the proposed PMA utilises magnetic wedges to form a fluid tight seal to the stator.

As an SMC slot wedge material, Somaloy 700 HR 3P (by Höganäs) was chosen which provides high mechanical strength (Young's modulus $=170 \mathrm{GPa}$ ) and it has a relatively high magnetic permeability: $\mu_{\max }=770$.

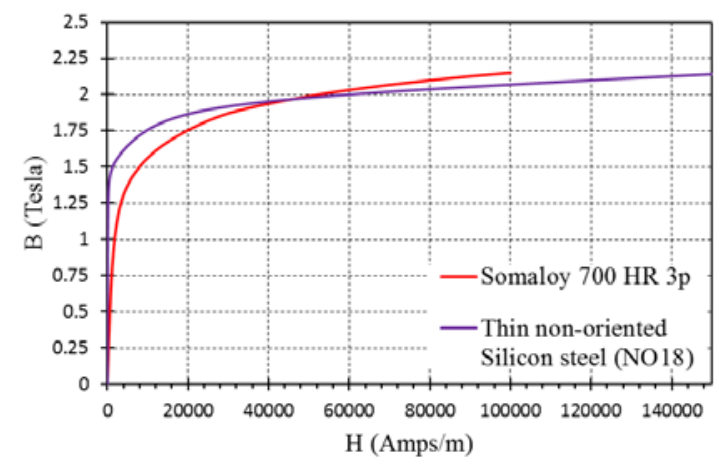

Fig. 1. $B / H$ curves for Somaloy 700HR 3p and NO18 silicon steel

As given in Fig. 1, the SMC wedge material saturates at lower magnetic field $(\approx 1.1 \mathrm{~T})$ compared to the laminated stator and rotor cores of the PMA. The SMC as a wedge material needs to be magnetically less permeable than silicon steels yet it should be much more permeable than air to increase phase inductance. High leakage flux at the slot opening will decrease the machine power density. For a fault tolerant design, it is however necessary to increase the slot leakage inductance as it is an important parameter to restrain short circuit current, which is a function of phase reactance, at high speeds.

Furthermore, magnetic wedges are worth investigation as they can reduce cogging torque [10] and magnetic field variation, thus reducing induced asynchronous spatial harmonics in the airgap due to large slot openings. Therefore, this work aims to optimise the slot shape and magnetic wedge thickness of the proposed permanent magnet alternators to achieve high power density along with preserving the machine fault tolerance.

\section{The Principals of Slot LEAKAGE INDUCTANCE IN A FAULT TOLERANT MACHINE DESIGN}

To make the PMA work well under no-load short circuit fault condition, a phase inductance design approach by altering the machine slot leakage inductance, dependent upon the SMC slot wedge dimensions has been proposed.

\section{A. Fault Tolerant Design}

The phase inductance, $L$ of the PMA consists of the synchronous inductance $L_{s}$, the harmonic leakage inductance $L_{h}$, the end leakage inductance $L_{e}$ and the slot leakage inductance $L_{\text {slot }}$. At higher speeds when the phase resistance $R \ll \omega L$, the short circuit current $I_{S}$ can be written as given in (1) [11]:

$$
I_{S} \approx \frac{E}{\omega L}
$$

where $E$ is back EMF and $\omega$ is the electrical angular frequency. Similarly, the slot leakage inductance $L_{\text {slot }}$ must be in the form:

$$
I_{s}<\frac{E}{\omega L_{\text {slot }}}
$$

The magnetic SMC wedges in the slot openings control the machine inductance and it is a design optimisation parameter that can be optimised to achieve about 1 p.u. inductance, which makes the machine fault tolerant under given specifications.

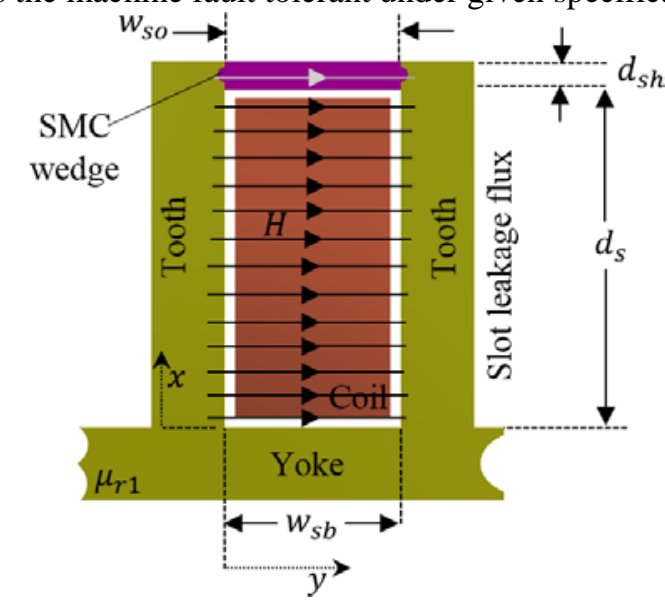

Fig. 2. Slot leakage inductance when a magnetic wedge exists in the slot openings

In Fig. 2, the slot leakage flux is depicted where the magnetic field crossing the slot in the $y$ - direction is called the slot leakage inductance. Using the co-energy and inductance relationship, per-slot leakage inductance can be written as given in (3) when SMC wedges exists in the tooth tip area and assuming no tapered area in the slot openings.

$$
L_{\text {sper-slot }}=N^{2}\left[\frac{\mu_{0} d_{s} L_{s t}}{3 w_{s b}}+\frac{\mu_{0} \mu_{r_{S M C}} d_{s h} L_{s t}}{w_{s o}}\right]
$$

The physical dimensions are shown in Fig. 2 and $\mu_{r_{S M C}}$ given in (3) is relative magnetic permeability of the SMC wedge of Somaloy 700HR 3p. The first term given in (3) considers the effective permeance of the coil is one-third of the normal permeance of the slot due to winding occupation. The second terms take the SMC permeability into account. With the SMC wedge design, the desired fault tolerance can be obtained as the machine slot leakage inductance can be altered by SMC wedge dimensions: $d_{s h}$ and $w_{s o}$ for the given stack length $L_{s t}$ in Table I.

\section{28 SLOT - 18 POLE DOUble LAYER Winding Permanent Magnet Alternator}

The fault tolerant PMA design requires four separate three phase power lanes and each lane should be physically isolated 
from the others. The four spacer teeth enables physical isolation between the lanes and leave 24 slots for the machine windings. $90^{\circ}$ electrical separation between the lanes has been achieved by the spacer teeth and the 16 rotor poles out of 18 poles cover the machine power lanes.

The machine winding configuration was arranged such that the diametrically opposite channels are electrically in phase with each other. A sub-machine winding configuration is shown in Fig. 3 below.

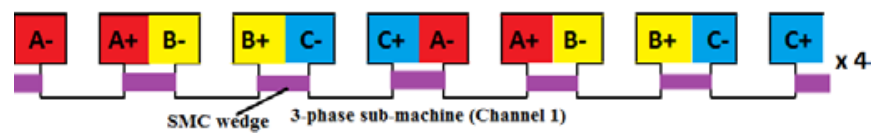

Fig. 3. PMA Winding configuration for a single channel

Due to the physical separation of the power lanes, as required for fault tolerance, the winding configuration for the proposed PMA becomes inherently un-balanced as the phase windings were not physically distributed equally around the stator circumference.

\section{A. FEA Design of 28 slot - 18 pole PMA}

The FEA model of the double layer winding PMA is illustrated in Fig. 4. The machine utilises thermally stable Samarium Cobalt PMs with a residual flux density $B_{r}$ of 1.04 $\mathrm{T}$ at $20^{\circ} \mathrm{C}$ and the air gap length was set to $1.5 \mathrm{~mm}$ regarding mechanical reliability of the machine.

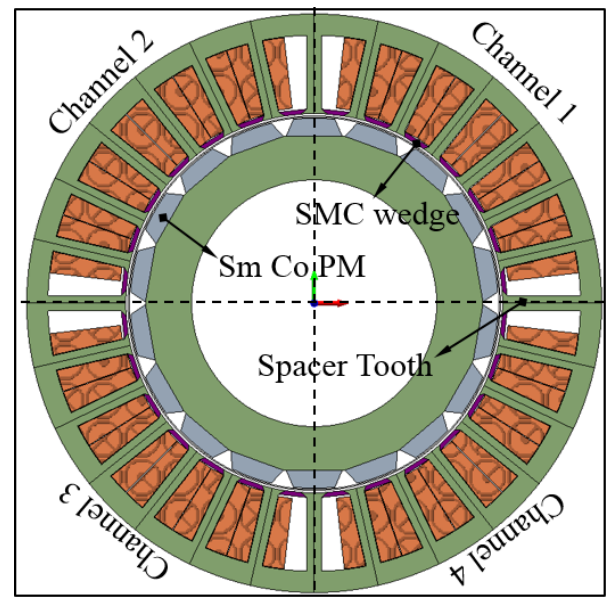

Fig. 4. 28 slot - 18 pole PMA model

After initial dimensioning of the PMA, the magnet shapes are optimized to reduce back EMF harmonics by using a parametric FEA model. The magnet pole pitch was set to $171^{\circ}$ electrical after optimisation of magnet upper corners as given in Fig. 5 to get higher back EMF at the end. The magnet shape optimisation reduced $5^{\text {th }}$, $7^{\text {th }}$ and higher order harmonic significantly.

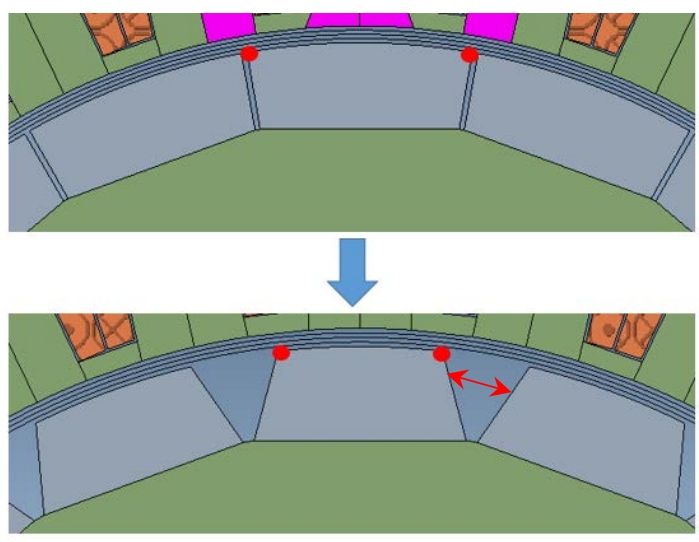

Fig. 5. Magnet shape optimisation - parallel magnetisation



Fig. 6. PMA sub-machine voltage waveforms on no load at $400 \mathrm{rpm}$

Both back EMF harmonics and cogging torque contribute to output power ripple. In Fig. 6, the back EMF waveforms are obtained when the $1.5 \mathrm{~mm}$ flat magnetic wedges are in place and the stator teeth, rotor inner/outer diameter and slot wedge dimensions were later optimized to meet the fault tolerance which is a function of stator slot and wedge dimensions. The total harmonic distortion (THD) of the back EMF for the chosen magnet shape is 5.22\% which was initially $11.16 \%$.

\section{B. The Effect of Slot Wedges on the PMA Power Output}

The effect of magnetic SMC wedges on the alternator cogging torque, back EMF, power output and fault tolerance is significant. While the thinner SMC wedges usually increases back EMF and alternator power, the thicker wedges reduce short circuit current due to increased slot leakage inductance. Therefore, the dimensions of the SMC is an optimisation parameter to achieve power requirement at low speed: $400 \mathrm{rpm}$ and short circuit restriction at rated speed: $15000 \mathrm{rpm}$. The output power quality is investigated when the alternator is connected to a 3-phase full wave diode rectifier cascaded with a constant DC voltage source as shown in Fig. 7. The output power and power ripple are investigated when the rectifier circuit is present in the FEA. 


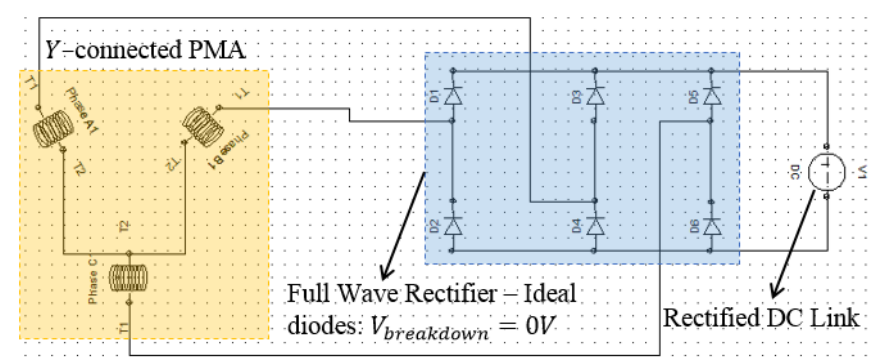

Fig. 7. A three phase sub-machine connected with a DC full wave rectifier

Initially, the wedge thickness is varied between $0.5 \mathrm{~mm}$ and $2.5 \mathrm{~mm}$ to see the DC power at the output, as given in Table II. As the PMA must satisfy 40 Watts power per channel, the wedge thickness above $2 \mathrm{~mm}$ does not satisfy the specification. Also, the thinner the wedge thickness the greater the output power ripple. The wedge thickness is optimised to achieve about 1 p.u. inductance to reduce short circuit current. The mechanical limitation on the minimum SMC wedge thickness is an important design consideration that can be overcome by choosing an SMC material with lower relative permeability as this would allow to thicken up the magnetic wedges by keeping the amount of the slot leakage flux through the wedges the same.

TABLE II. WEDGE THICKNESS VS. DC OUTPUT POWER

\begin{tabular}{|c|c|c|}
\hline Wedge Thickness (mm) & DC Power (W) & Power Ripple (\%) \\
\hline 0.5 & 109.68 & 19.16 \\
\hline 0.75 & 97.59 & 21.97 \\
\hline 1 & 83.5 & 24.31 \\
\hline 1.5 & 59.86 & 33.13 \\
\hline 2 & 37.97 & 44.91 \\
\hline 2.5 & 22.45 & 64.26 \\
\hline
\end{tabular}

The short circuit current are greatly reduced when the SMC wedges of $1.5 \mathrm{~mm}$ are in place. The rms short circuit current at steady state when SMC wedges are present is $19.9 A_{r m s}$ while it is $43.52 A_{\text {rms }}$ for the PMA with open slots. The transient short circuit response at rated speed on no load condition is compared in Fig. 8 with and without magnetic wedges.



Fig. 8. PMA Phase B short circuit current transients on no load
Fig. 9 also demonstrates the cogging torque reduction for the PMA with and without wedges. More than 10 fold peak to peak cogging torque reduction was obtained for the PMA with $1.5 \mathrm{~mm}$ SMC wedges.



Fig. 9. Cogging torque in 28 slot - 18 pole PMA with and without wedges

\section{Un-Balanced Alternator Currents}

In Table II, it can be noted that the percent DC power ripple in $Y$-connected PMA output is around 33\% for $1.5 \mathrm{~mm}$ wedge thickness. This states that the PMA sub-machines generate unbalanced voltage and current waveforms due to phase inductance differences between the machine phases. Due to the existence of spacer teeth, each sub-machine experiences an end effect implying that the side phases (i.e. Phases A \& C) have less inductance whereas the middle phase (B) has higher inductance due to a higher mutual inductance. Therefore, the proposed 28 slot - 18 pole PMA will not have a perfectly balanced configuration.



Fig. 10. $Y$-connected sub-alternator phase currents - unbalanced

Fig. 10 shows the un-balanced phase currents when the $Y$ connected sub-PMA is coupled to a rectifier circuit. In this case, Phae B gives about $27.5 \%$ less current and it has higher inductance. In order to balance a machine with inherently unbalanced winding configuration, a set of methods has been proposed in this work. This in turn results in smoother output DC power in the proposed double layer PMA.

\section{Method 1 - Wedge Thickness in Spacer Teeth}

In the first method, the SMC wedges in the spacer teeth slot openings have been thickened to increase slot leakage inductance of the end phases which are Phase A and Phase $\mathrm{C}$ for the double layer PMA. All other magnetic wedges are left as they are. The thicker the wedges in the spacer teeth, the higher the self-inductance of the side phases of a sub-machine. 


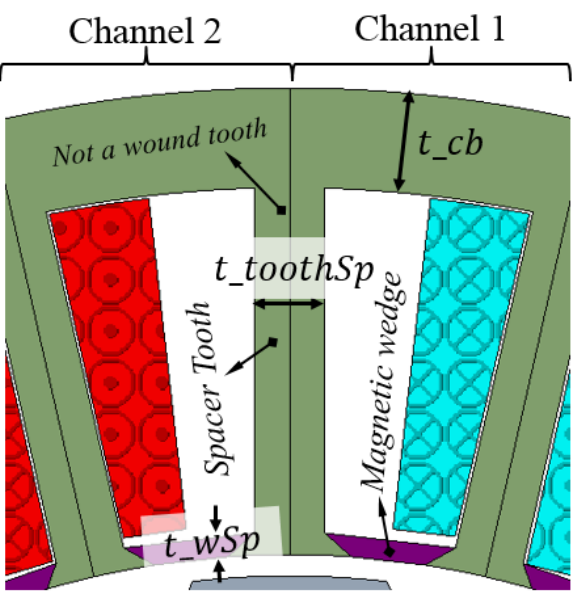

Fig. 11. End effect in sub-alternators

As given in Fig. 11, the spacer tooth thickness ( $t_{-}$toothSp) and the spacer tooth wedge thickness $\left(t_{-} w S p\right)$ are two important parameters to vary slot leakage of the end phases shown in Fig. 11. The effect of (t_toothSp) on the DC output power magnitude and ripple is investigated in Table III below.

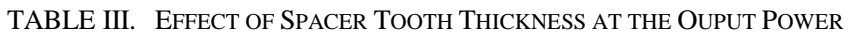

\begin{tabular}{|c|c|c|c|c|c|c|c|}
\hline $\begin{array}{c}\left(\begin{array}{c}\text { t_toothSp) } \\
\text { (mm) }\end{array}\right. \\
\text { Power ripple } \\
\text { (\%) }\end{array}$ & 33.1 & 35.1 & 34.4 & 36.6 & 38.2 & 41 & 41.5 \\
\hline $\begin{array}{c}\text { Output } \\
\text { Power (W) }\end{array}$ & 59.8 & 59.2 & 57.8 & 56.1 & 54.7 & 53.9 & 53 \\
\hline
\end{tabular}

As tabulated in Table III, the DC output power is linked with physical dimensions of the spacer tooth as it is not only a physical separation between the sub-machines but it varies the slot leakage inductance of the end phases. Similarly, the effect of spacer tooth wedge thickness on the output power is examined in Fig. 12 when $t_{-}$toothSp is $3 \mathrm{~mm}$.

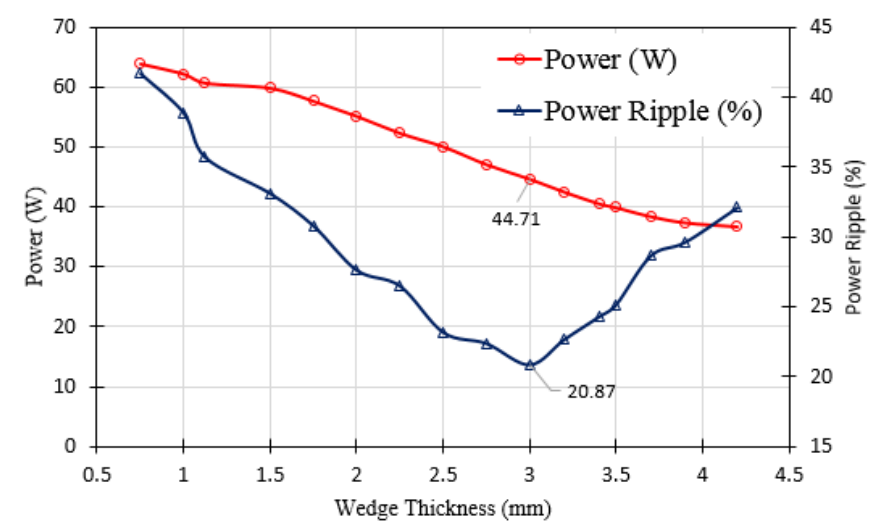

Fig. 12. Power ripple for different spacer tooth wedge thickness

As shown in Fig. 12, the power ripple on the constant DC link is reduced to $20.87 \%$ and the sub-machine achieves the minimum power requirement. This leads to more balanced current waveforms in the $Y$-connected alternator as depicted in Fig. 13.

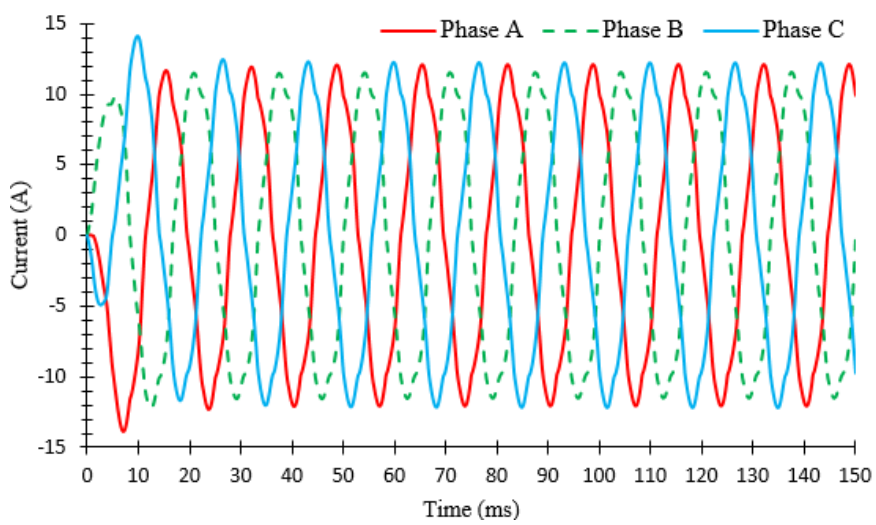

Fig. 13. Y-connected sub-alternator phase currents - more balanced

\section{E. Method 2-Magnetic Wedge Selection in the Middle Slot of a Sub-Machine}

The SMC magnetic wedge coupling only Phases A and C, as shown in Fig. 14, can be adjusted to give more balanced current waveforms. Firstly, a number of materials with different relative permeability have been investigated, as illustrated in Fig. 15. Secondly, the optimum wedge thickness was found. In this case, $1.5 \mathrm{~mm}$ wedge thickness achieves the lowest ripple (26.6\%), when the relative permeability, $\mu_{r_{\max }}$ of the material is 1000 .

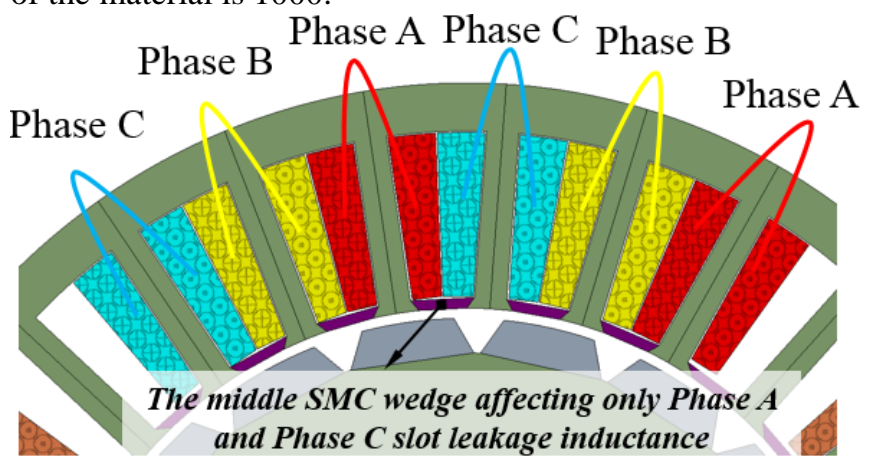

Fig. 14. The middle magnetic wedge coupling Phase A \& C

When $\mu_{r_{\max }}$ is low and the material saturates at a lower flux density, the output power ripple will be significant, up to $49 \%$. Fig. 15 proves that the magnetic wedge linking end phases in the middle is an important optimisation parameter to achieve smoother power at the output.

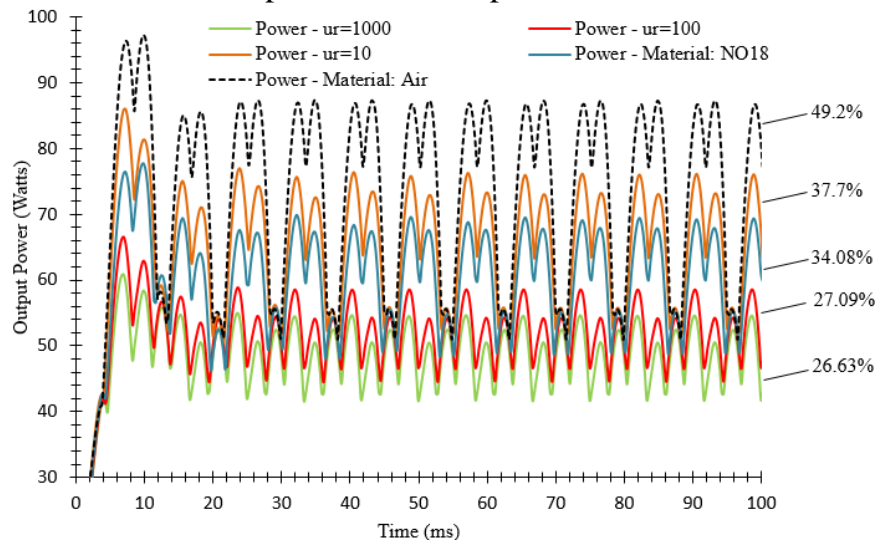

Fig. 15. Rectified power output of a sub-PMA and ripple percent 


\section{24 Slot - 20 Pole Single Layer Winding Permanent MAGNET ALTERNATOR}

An alternative configuration is shown in Fig. 16, utilizing single layer windings and thinner spacer teeth between individual coils. The machine does not suffer from unbalanced current and voltage waveforms significantly as the mutual inductance $(7 \mu \mathrm{H})$ coupling between the coils is very low.

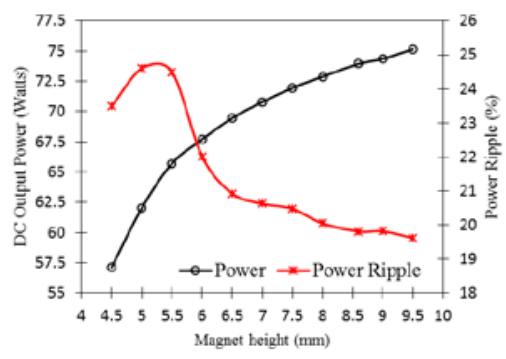

(a)

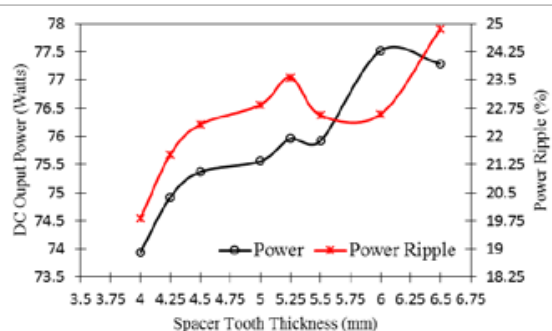

(d)

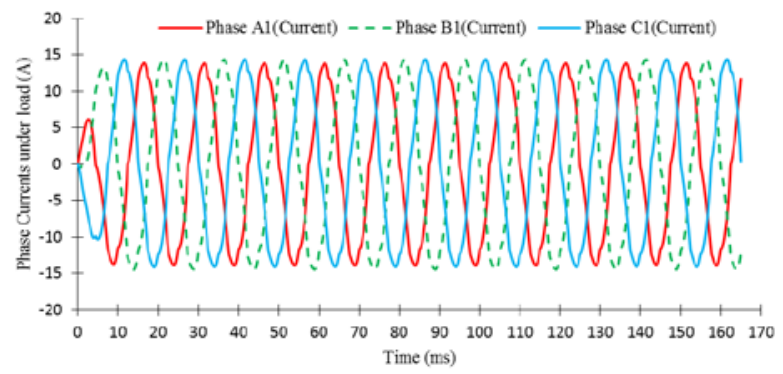

(g)

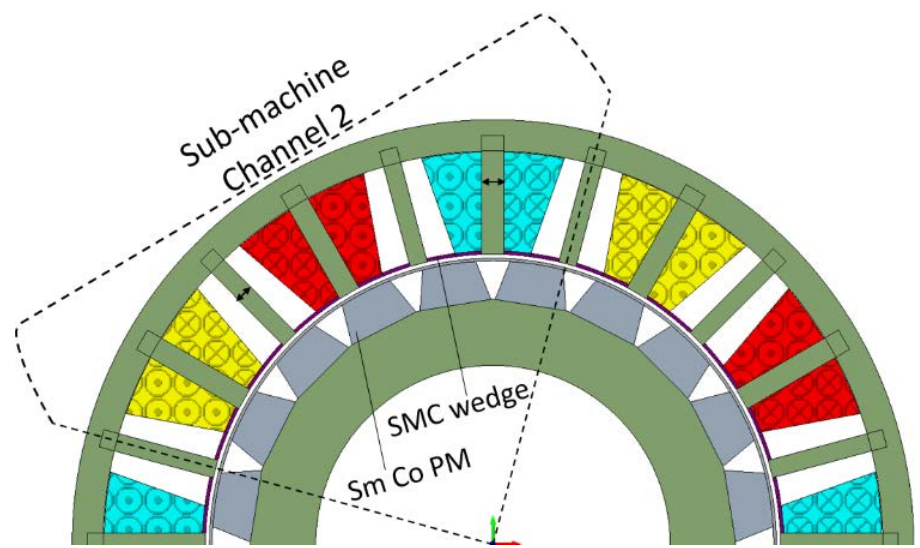

Fig. 16. 24 slot - 20 pole PMA model -half

2-D FEA optimisation has been performed to reduce power ripple at the rectifier output. The results are plotted in Fig.17 to choose the optimum machine dimensions.

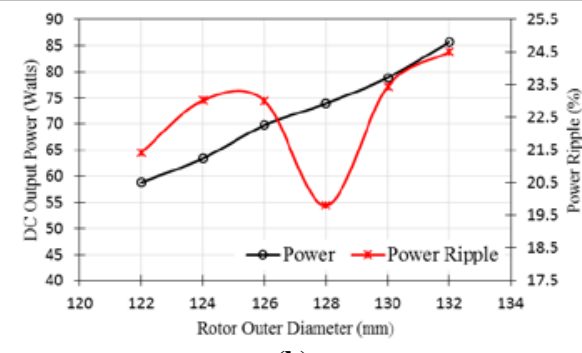

(b)

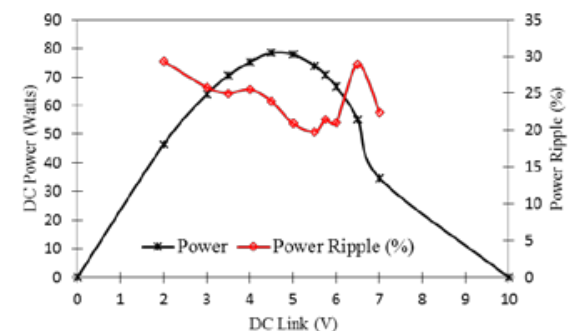

(e)

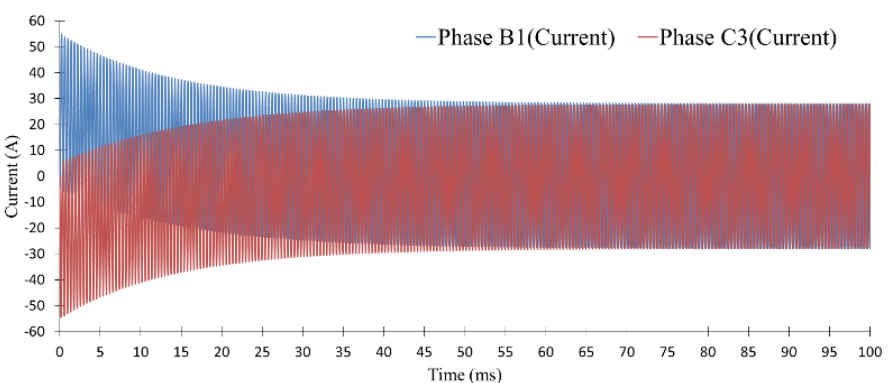

(h)
Fig. 17. (a), (b), (c), (d), (e) - FEA optimisation of the PMA to obtain smoother power output in each sub-machine; (f) Sub-machine back EMF at 400 rpm; (g) Highly balanced $Y$ - connected sub-alternator phase currents; (h) Short circuit current transients at $15000 \mathrm{rpm}$

24 slot - 20 pole single layer PMA gives about 19.8\% power ripple and achieves 73.9 Watts power at low speed: 400 rpm. The short circuit currents on no-load condition is $19.7 A_{\text {rms }}$ meets the short circuit criterion at rated speed. The key machine dimensions and features are given in Table IV.

TABLE IV. 24 SLOT- 20 POLE PMA KEY PARAMETERS

\begin{tabular}{|c|c|}
\hline Tooth thickness & $5 \mathrm{~mm}$ \\
\hline
\end{tabular}

\begin{tabular}{|c|c|}
\hline Spacer (Thin) Tooth thickness & $4 \mathrm{~mm}$ \\
\hline Slot opening & $12.985 \mathrm{~mm}$ \\
\hline Stator core back thickness & $7 \mathrm{~mm}$ \\
\hline Air gap length & $0.864 \mathrm{~mm}$ \\
\hline Inconel 718 sleeve thickness & $0.636 \mathrm{~mm}$ \\
\hline SMC wedge thickness & $1.5 \mathrm{~mm}$ \\
\hline Magnet thickness & $8.6 \mathrm{~mm}$ \\
\hline
\end{tabular}




\begin{tabular}{|c|c|}
\hline Rotor inner diameter & $80 \mathrm{~mm}$ \\
\hline Rotor outer diameter & $128 \mathrm{~mm}$ \\
\hline Stator outer diameter & $190 \mathrm{~mm}$ \\
\hline Bare slot area & $330 \mathrm{~mm}^{2}$ \\
\hline Number of turns & 58 \\
\hline Stack length & $30 \mathrm{~mm}$ \\
\hline
\end{tabular}

\section{NO - LOAD PMA LOSS ANALYSIS AND COMPARISON}

Rotor eddy current losses due to space (MMF) harmonics can be significant if a fractional slot concentrated winding in single layer winding configuration is chosen [12]. Single layer windings inherently produce more spatial harmonics compared to double layer windings implying higher rotor losses. In order to understand rotor losses in the proposed single and double layer PMAs, tangential $\mathrm{H}$ field $(\mathrm{Ht})$ harmonics across the stator bore can be investigated. In Fig. 18, spatial MMF harmonics for the double layer and single layer PMAs are shown.
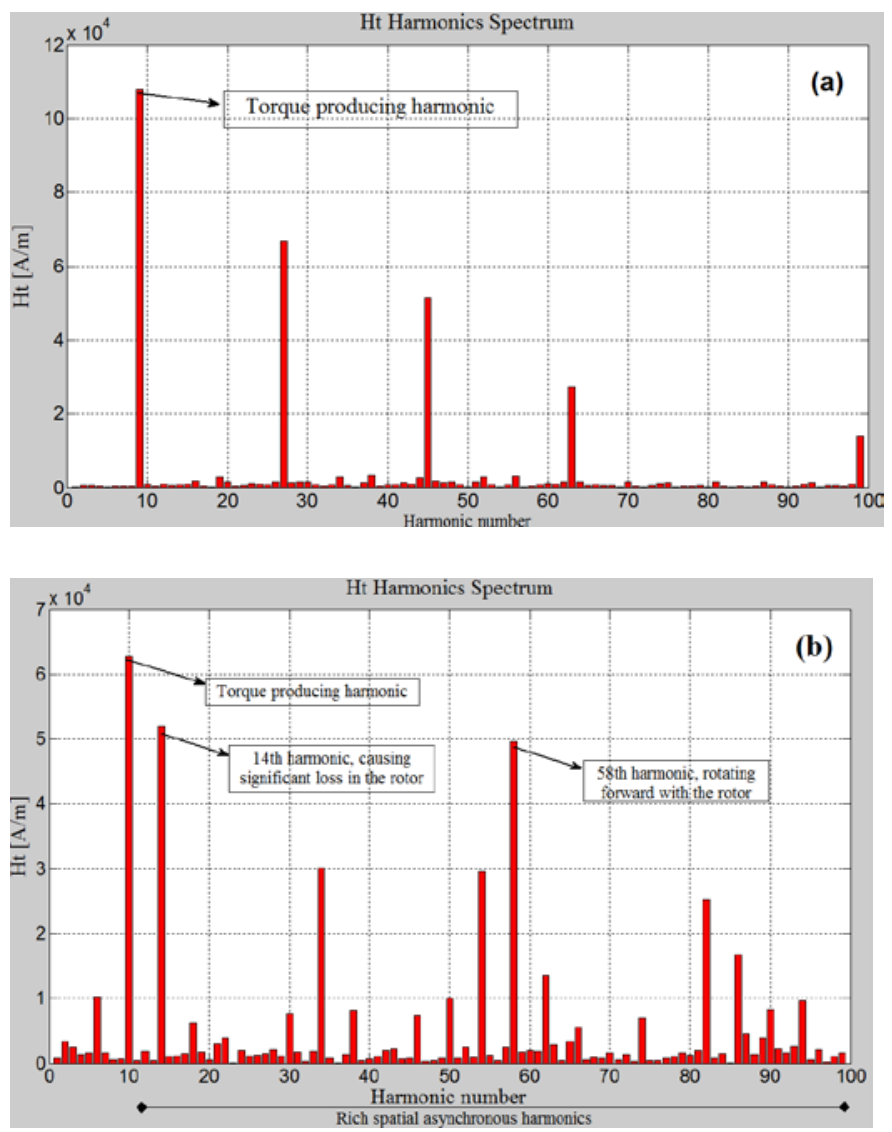

Fig. 18. Spatial MMF harmonics for: (a) 28s18p PMA, (b) 24s20p PMA

Due to rich air gap spatial harmonic content of single layer 24 slot - 20 pole PMA, it is expected that this configuration leads to higher rotor core losses. Nonetheless, double layer 28 slot -18 pole PMA eliminates sub and super harmonics significantly and gives notably less rotor core losses as depicted in Fig. 19 below. Although the 28 slot -18 pole machine employs inherently un-balanced winding configuration, this negative effect was greatly reduced by the approaches discussed previously.

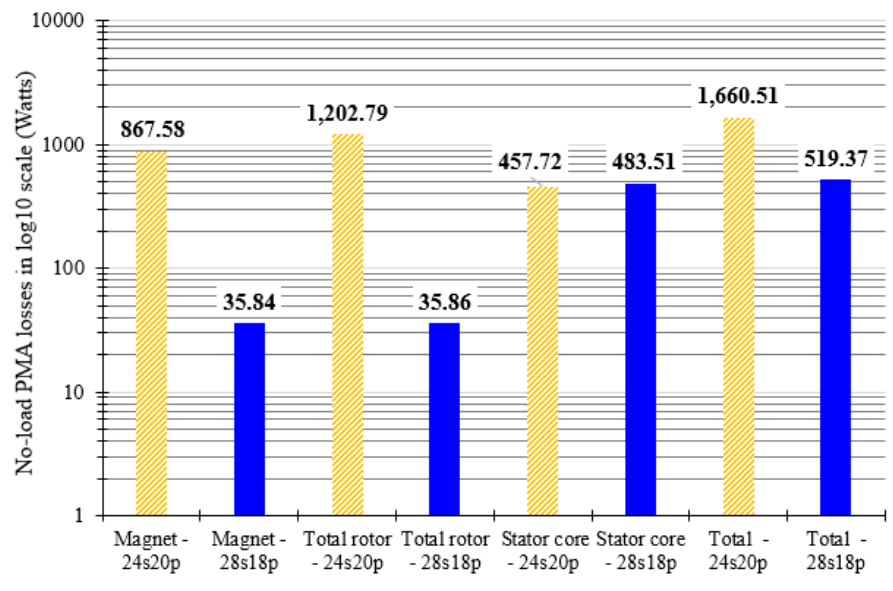

Fig. 19. PMAs loss comparison on no load condition at rated speed

It should be noted the efficiency merits of the PMAs are not of concern as the proposed machines do not target any specified power output at high speeds. The design optimisation considers a power requirement at low speeds only. The rated speed losses as shown in Fig. 19 would not be a problem in the final design as the machine will utilise flooded rotor and stator, which will improve the thermal performance of the machine significantly.

\section{CONCLUSION}

In this paper, single layer 28s18p and double layer 24s20p PMAs utilising SMC slot wedges have been proposed for an aerospace alternator. The PMAs have been optimized using 2D-FEA to get smoother power at the rectified output. The effect of SMC slot wedges on the balance of phase windings have also been described. It is shown that the proposed PMAs achieves similar power ripple (i.e. about 20\%) and satisfy all fault tolerance requirements yet single layer 24s20p machine produces significantly high rotor losses at rated speed. Due to strict fault tolerance requirements, the power ripple at the output of the PMAs is relatively high. The principal cause of the high power ripple is that the winding layout in the proposed machines form four sub-machines next to each other, implying that the winding layouts are not conventional. In terms of the machine performance, 28s18p PMA, however, becomes a better option.

\section{REFERENCES}

[1] R. M. Saunders and R. H. Weakley, "Design of Permanent-Magnet Alternators," in Transactions of the American Institute of Electrical Engineers, vol. 70, no. 2, pp. 1578-1581, July 1951.

[2] N. J. Baker, D. J. Smith, M. C. Kulan and S. Turvey, "Design and performance of a segmented stator permanent magnet alternator for aerospace," 8th IET International Conference on Power Electronics, Machines and Drives (PEMD 2016), Glasgow, 2016, pp. 1-6.

[3] N. J. Baker, D. J. Smith, M. C. Kulan and S. Turvey, "Design and performance of a Segmented Stator Permanent Magnet Alternator for Aerospace," in IEEE Transactions on Energy Conversion, vol. PP, no. 99, pp. 1-1.

[4] H. Wang, Z. Hao and S. Yang, "Analysis of aviation fault-tolerant generation system with flux weakening control," 2016 International Conference on Electrical Systems for Aircraft, Railway, Ship Propulsion 
and Road Vehicles \& International Transportation Electrification Conference (ESARS-ITEC), Toulouse, 2016, pp. 1-6.

[5] A. Cavagnino, Z. Li, A. Tenconi and S. Vaschetto, "Integrated generator for more electric engine: Design and testing of a scaled size prototype," 2012 IEEE Energy Conversion Congress and Exposition (ECCE), Raleigh, NC, 2012, pp. 542-549.

[6] D. Maga, M. Zagirnyak, and D. Miljavec, “Additional Losses in Permanent Magnet Brushless Machines”, EPE-PEMC 2010, 14th International Power Electronics and Motion Control Conference, 2010.

[7] J. F. Gieras, Advancements in Electric Machines: Springer, 2008

[8] A. Reinap and M. Alakula, "Impact of Soft Magnetic Material on Construction of Radial Flux Electrical Machines," in IEEE Transactions on Magnetics, vol. 48, no. 4, pp. 1613-1616, April 2012.

[9] A. Tessarolo, F. Luise, M. Bortolozzi and M. Mezzarobba, "A new magnetic wedge design for enhancing the performance of open-slot electric machines," 2012 Electrical Systems for Aircraft, Railway and Ship Propulsion, Bologna, 2012, pp. 1-5.

[10] J. Rao and R. Qu, "Magnetic slot wedge design for high power permanent magnet traction motors," 2015 IEEE Magnetics Conference (INTERMAG), Beijing, 2015, pp. 1-1.

[11] Guo, H., Xu, J., \& Kuang, X. A novel fault tolerant permanent magnet synchronous motor with improved optimal torque control for aerospace application. Chinese journal of aeronautics, 28(2), 535-544., (2015)

[12] G. J. Atkinson, B. C. Mecrow, A. G. Jack, D. J. Atkinson, P. Sangha and M. Benarous, "The Analysis of Losses in High-Power Fault-Tolerant Machines for Aerospace Applications," in IEEE Transactions on Industry Applications, vol. 42, no. 5, pp. 1162-1170, Sept.-Oct. 2006.

\section{BIOGRAPHIES}

Mehmet C. Kulan received the BSc degree in electrical and electronics engineering from Bilkent University, Ankara, Turkey in 2011 and MSc degree from the University of Newcastle Upon Tyne U.K., in 2013, where he is currently working toward the Ph.D. degree as part of Electrical Power Group, School of Electrical and Electronic Engineering.

Nick J. Baker received a MEng Degree in Mechanical Engineering from Birmingham University, UK, in 1999 and a Ph.D. from Durham University U.K in 2003 for work in electrical machine design for marine renewable energy devices. He is presently a Senior Lecturer at Newcastle University's Electrical Power Group. Nick is a machine designer with research projects across the automotive, aerospace and renewable energy sector.

Simon Turvey received an HNC from North Birmingham Poly-Technic in 1976. He is currently working as a specialist engineer in Rolls-Royce Control Systems Research and Technology group where his interests include dedicated electrical machines for gas turbine engines, power conversion and wide bandgap semiconductors. 